Research Article

\title{
Hydromechanical Simulation of Tunnel Excavation in Rock Considering a Nearby Karst Cave
}

\author{
Huiling Zhao $\left(\mathbb{D},{ }^{1}\right.$ Fan Zhang $\left(\mathbb{D},{ }^{1}\right.$ and Xupeng Yao ${ }^{2}$ \\ ${ }^{1}$ Department of Civil Engineering, Shanghai University, Shanghai 200444, China \\ ${ }^{2}$ College of Civil Engineering, Tongji University, Shanghai 200092, China
}

Correspondence should be addressed to Fan Zhang; fanzai@shu.edu.cn

Received 13 October 2021; Accepted 17 November 2021; Published 18 December 2021

Academic Editor: Debiao Meng

Copyright (C) 2021 Huiling Zhao et al. This is an open access article distributed under the Creative Commons Attribution License, which permits unrestricted use, distribution, and reproduction in any medium, provided the original work is properly cited.

Tunnel excavation tends to be affected by karst cavities in karst areas. Some cavities that are at low risk of causing safety issues without treatment tend to be ignored in the design and construction of tunnels to reduce costs. It is necessary to gain a better understanding of the effect of such a cavity on the seepage around a tunnel, the deformation of the surrounding rock, and the stress of the tunnel lining. In this paper, a two-dimensional rock-tunnel hydromechanical model with a karst cave was established with FLAC3D finite difference software to simulate the tunnel excavation with the consideration of seepage. Numerical simulations were performed to analyze the deformation of the surrounding rock, the seepage field of the surrounding rock, and the stress of the tunnel lining, and the results were compared for scenarios when the karst cave is at different locations relative to the tunnel. These results can provide a reference for the design and construction of tunnel engineering in rock with karst caves.

\section{Introduction}

With the development of the mileage and scope of tunnels, tunnels are inevitably constructed in some complicated geological areas. An increasing number of tunnels pass through karst areas, in which microscale cavities readily develop along the fault planes and joints in limestone due to weathering and chemical corrosion. The unpredictable occurrence of cavities presents challenges to tunnel construction $[1,2]$. The existence of karst cavities around a tunnel certainly affects the design of the tunnel and the safety of the construction of the tunnel [3-8].

Recently, the problems associated with the excavation and support of tunnels in karst ground have attracted increasing attentions. Scholars have explored which are the main influencing factors for tunnel excavation in karst areas, and the safe distance between tunnels and karst caves has been studied. Huang et al. [9] proposed an evaluation model of karst cave development conditions, construction conditions, and control measures, performed a statistical analysis, and concluded that the groundwater level, support structure, and surrounding rock quality were the main factors influencing the stability of tunnels in karst areas. Wang et al. [10] established a prediction model for the safe thickness of the roof of karst caves and found that the span of karst caves influenced the cave stability more significantly than the filling degree of karst caves and that the height-to-span ratio of karst caves had little relation to the safe thickness of the cave roof. Huang et al. [11] analyzed the influence of the distance between the roof and tunnel and the diameter, width, and filling degree of a karst cave on the deformation of subway tunnel segments after excavation, considering the fluid-solid coupling effect. Chen and Sha [12] studied the stress-strain characteristics of the surrounding rock and supporting structure of a tunnel with a superlarge karst cave at different distances through field tests and numerical simulations. Zhao et al. [13] studied the stability of a rock pillar on a concealed karst cave in front of a tunnel and calculated the safe thickness of the rock pillar to prevent water inrush. Shan et al. [14] analyzed the safe thickness between a tunnel and a nearby hidden cave and the factors influencing the rock-breaking mechanism and conducted numerical simulations and multiple regression analyses to study the safe distance between the tunnel and the karst cave. 
Wang et a. [15] studied the influence of surrounding rock parameters on the collapse surface of a karst rock mass under a tunnel and proposed a formula for the minimum safe thickness to prevent rock pillar collapse. These studies show that some cavities with well-developed hydraulic conduits located at the key position need to be treated; without treatment, they may introduce a high risk to tunnel construction safety, possibly leading to water inrush, mud inrush, and even collapse [16-20]. Nevertheless, some cavities with a low risk of causing safety issues tend to be ignored in the design and construction of tunnels to reduce costs. Thus, it is necessary to gain a better understanding of the effect of the cavity on the seepage around the tunnel, the deformation of the surrounding rock, and the stress of the tunnel lining.

In this paper, the deformation of the surrounding rock, the seepage field of the surrounding rock, and the stress of the tunnel lining are analyzed by means of numerical simulations of several scenarios in which the karst cave is at different locations relative to the tunnel [21], and the results are compared. The results can provide some reference for the design and construction of tunnel engineering in water-rich areas with karst caves.

\section{Establishment of the Coupled Hydromechanical Simulation}

2.1. Establishment of the Finite Difference Numerical Model. Based on a tunnel project in Yunnan Province, China, a typical section is selected to simulate the stability of the surrounding rock and the change in the seepage field during tunnel excavation. The depth of the tunnel is $60 \mathrm{~m}$. The width and the height of the tunnel are $12 \mathrm{~m}$ and $8.5 \mathrm{~m}$, respectively. The rock range considered in the numerical model is about 4 times the diameter of the tunnel. The top boundary is the ground surface, and the bottom boundary is $36 \mathrm{~m}$ below the tunnel. The model is $100 \mathrm{~m}$ wide and $110 \mathrm{~m}$ high. The lateral boundaries of the model are set horizontal displacement constraints, and the bottom boundary is set a fixed displacement constraint. In order to simplify the hydrologic condition, the initial saturation of the model is set as 1.0. The initial stress is calculated according to gravity stress of rock mass. The pore water pressure on the top boundary of the model is set as 0 , and the other boundaries are impermeable boundaries. The permeable boundary is set on the inner side of the tunnel during excavation, where the water pressure is initially set as 0 . The karst cave is taken as the shape of an ellipse. The long axis of the karst cave is $5 \mathrm{~m}$, and the short axis is $3 \mathrm{~m}$. The model meshing details and geometry of rock domain and tunnel lining are displayed in Figure 1. The model meshing is according to mesh convergence study. In the zone near to tunnel lining, higher mesh density has been provided for attaining desired accuracy. The mesh size is increased away from the tunnel in order to make the model computationally efficient.

The Mohr-Coulomb elastic-plastic model is adopted for the surrounding rock, and an elastic model is adopted for the support. According to the Chinese code for the design of highway tunnels [22], the material parameters of the

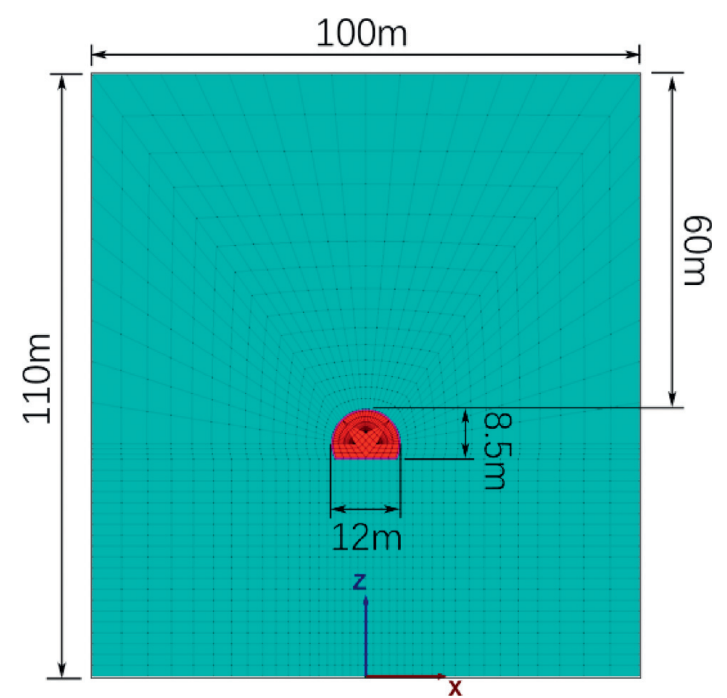

Figure 1: Numerical model for tunnel excavation simulation.

surrounding rock and supporting structure in the numerical simulation are shown in Table $1[23,24]$. The primary support of this section is made of C25 shotcrete with a thickness of $0.3 \mathrm{~m}$. The secondary support is a C25 monolithic concrete structure with a thickness of $0.7 \mathrm{~m}$.

2.2. Determination of the Working Conditions. In order to study the influences of different distances and positions of a karst cave on tunnel excavation, six working conditions are established, as shown in Figure 2. For working conditions 1, 2 , and 3, the karst caves are located on the left side of the tunnel, and the caves are $2 \mathrm{~m}, 4 \mathrm{~m}$, and $6 \mathrm{~m}$ away from the left side of the tunnel, respectively. For working conditions 4 and 5, the caves are located above and below the tunnel, respectively. Under working condition 6 , the center of the karst cave is $45^{\circ}$ counterclockwise from the central axis of the tunnel. In the latter 3 cases, the karst caves are $2 \mathrm{~m}$ away from the tunnel boundary.

\section{Comparison and Results Analysis}

\subsection{Influence of Distance of Cave to the Tunnel}

3.1.1. Stress Field of the Surrounding Rock. The state of stress balance in the rock is disturbed due to the tunnel excavation. The redistribution of the stress in the surrounding rock has changed the permeability of the rock, accompanied by the varying pore water pressure in the surrounding rock. The variation in pore water pressure can also affect the distribution of the stress field in the surrounding rock. Actually, the pore water pressure and rock stress are interdependent. The stress field and seepage field finally have reached a relative equilibrium state under the condition of fluid-solid coupling. Figure 3 shows the horizontal and vertical stress contour plots of the tunnel and surrounding rock in the absence of a karst cave. Figures 4 and 5 show the horizontal stress contour plot and the vertical stress contour plot, respectively, for working conditions 1,2 , and 3 . 
TABLE 1: Material parameters of the numerical model.

\begin{tabular}{lcccccc}
\hline & Elastic modulus $(\mathrm{GPa})$ & Poisson's ratio & Friction angle $\left(^{\circ}\right)$ & $\begin{array}{c}\text { Volumetric weight } \\
\left(\mathrm{kN} \cdot \mathrm{m}^{-3}\right)\end{array}$ & $\begin{array}{c}\text { Cohesion } \\
(\mathrm{MPa})\end{array}$ & $\begin{array}{c}\text { Permeability coefficient } \\
\left(\mathrm{cm} \cdot \mathrm{s}^{-1}\right)\end{array}$ \\
\hline Rock & 6 & 0.25 & 40 & 26 & 0.9 & $4.5 \times 10^{-4}$ \\
Tunnel support & 30 & 0.2 & - & 24 & - & $1.5 \times 10^{-8}$ \\
\hline
\end{tabular}

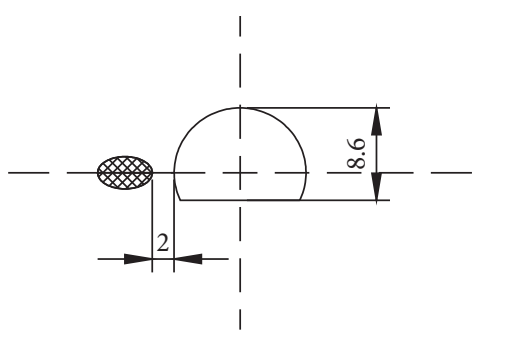

(a)

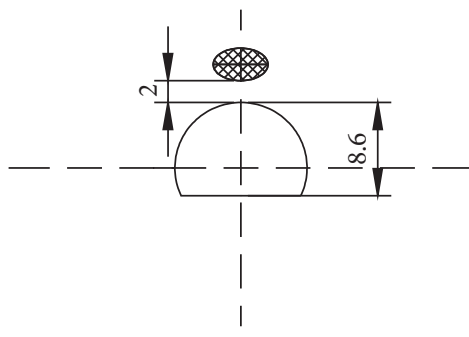

(d)

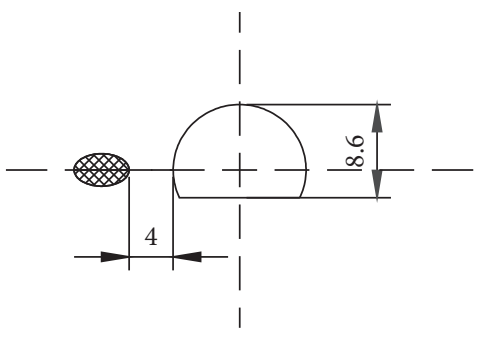

(b)

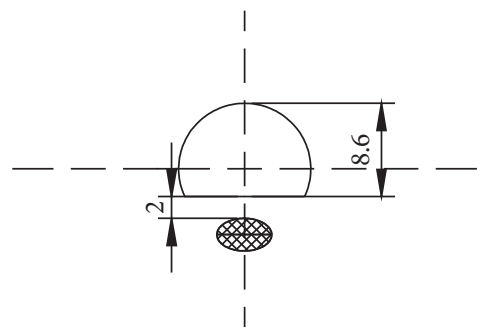

(e)

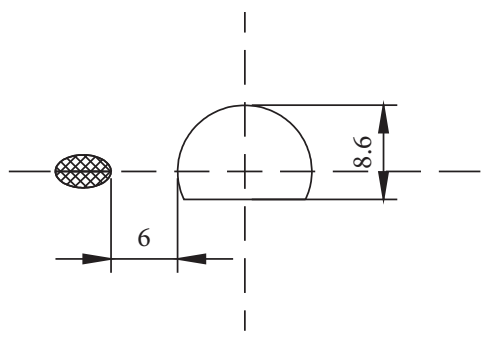

(c)

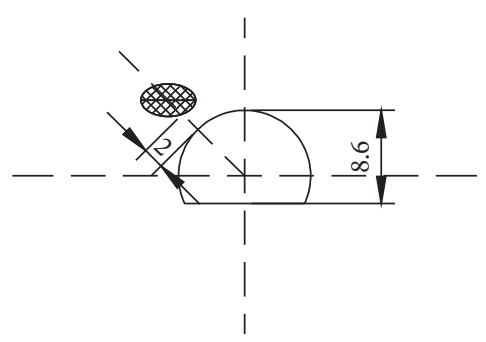

(f)

FIGURE 2: The cave location in 6 different working conditions. (a) Working condition 1. (b) Working condition 2. (c) Working condition 3. (d) Working condition 4. (e) Working condition 5. (f) Working condition 6.
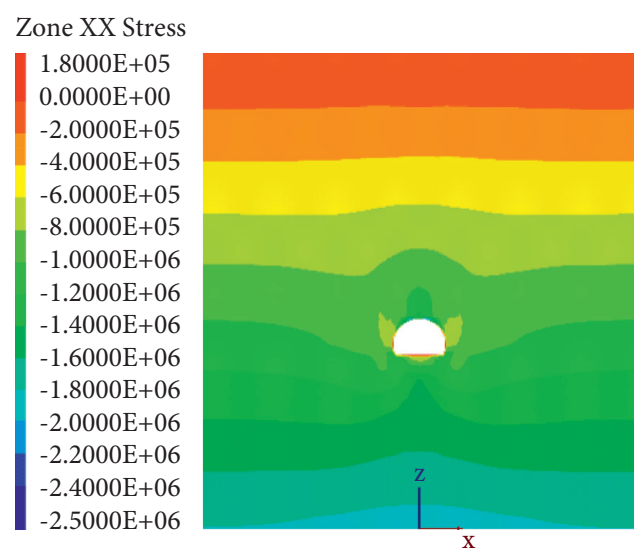

(a)
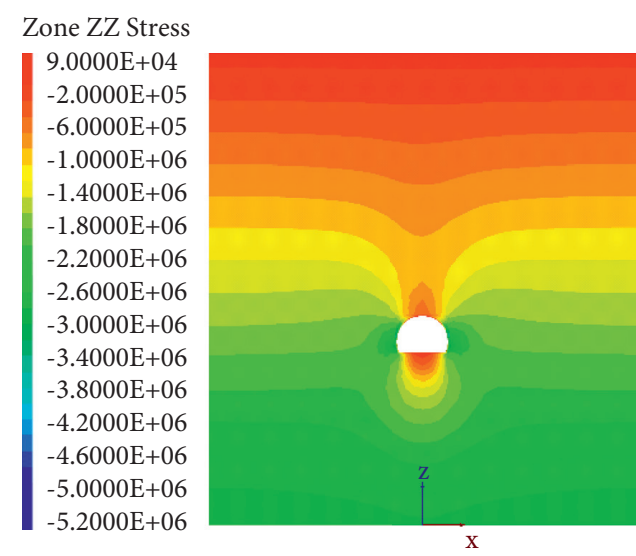

(b)

Figure 3: Stress contour plots without a karst cave. (a) Horizontal stress contour plot. (b) Vertical stress contour plot.

It can be seen from Figure 4 that the horizontal compressive stresses of the surrounding rock on both sides of the tunnel have changed compared with those of the working condition without a karst cave. Due to the existence of the cavern, the excavation stress release on the left and right side of the tunnel is asymmetric. When the cave is close to the tunnel in working condition 1 , the excavation stress release area reaches the cave resulting in that the compressive stress decreases about $16 \%$ between the cave and the tunnel.
Figure 5 shows the vertical compressive stress of the surrounding rock in working conditions 1 to 3 . The vertical compressive stress at the hance of the tunnel on the side with cave increases significantly in working conditions 1 and 2; in particular working condition 1 has increased from $2.4 \mathrm{MPa}$ to $4.6 \mathrm{MPa}$. At the same time, the compressive stress of the surrounding rock directly above and below the tunnel also increases by $13 \%$ and $10 \%$ in working condition 1 . Similarly, the vertical stress distribution of surrounding rock in 


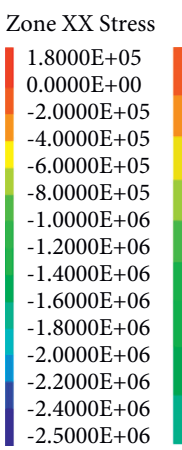

$-2.5000 \mathrm{E}+06$

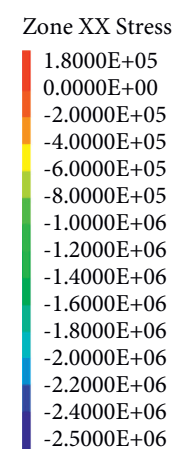

(a)

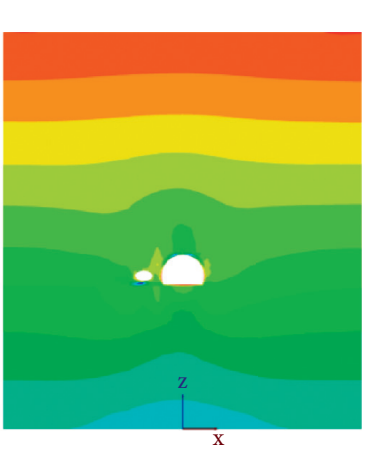

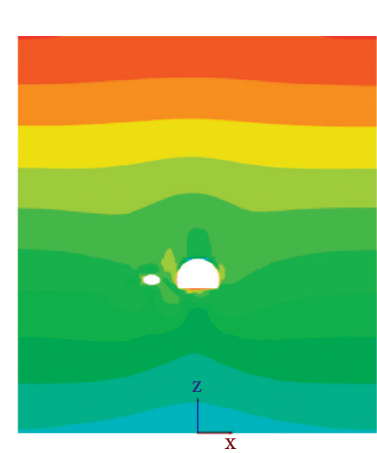

(b)

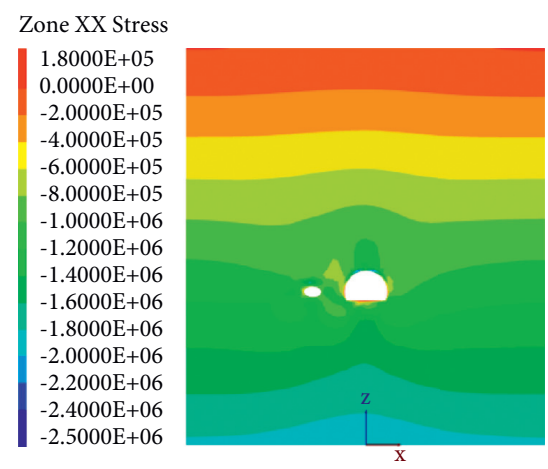

(c)

FIgURE 4: Horizontal stress contour plots. (a) Working condition 1. (b) Working condition 2. (c) Working condition 3.
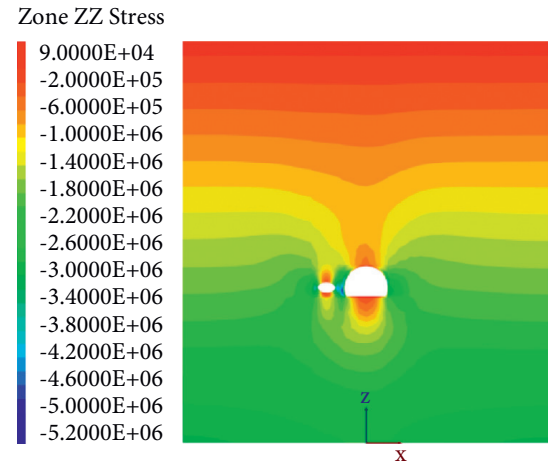

(a)

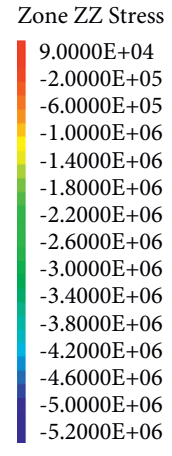

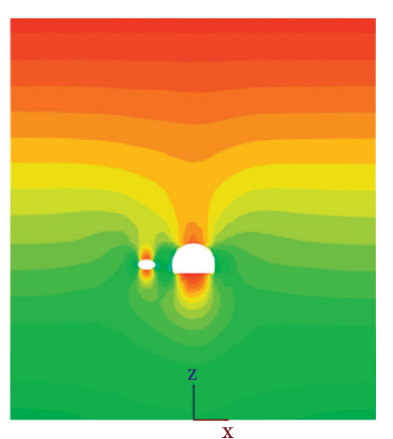

(b)

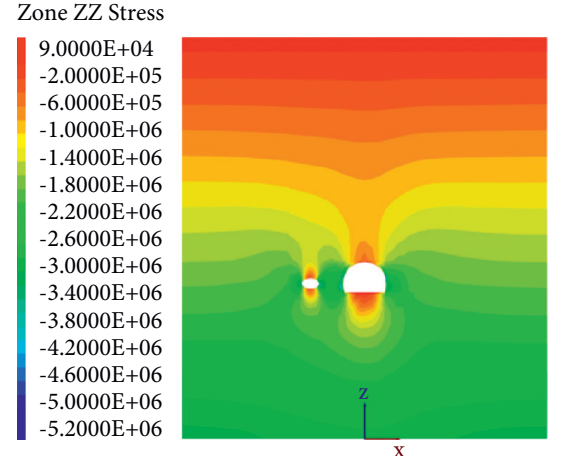

(c)

Figure 5: Vertical stress contour plots. (a) Working condition 1. (b) Working condition 2. (c) Working condition 3.

working condition 2 and working condition 3 is similar to that in working condition 1 , but the increment decreases obviously. It can be seen that a cave near to the tunnel leads to an increase in the compressive stress of the surrounding rock at the cave side of the tunnel.

3.1.2. Seepage Field. Key points of the tunnel lining are selected to monitor the seepage field. Point A locates at the vault, point $B$ locates at the left hance, point $C$ locates at the right hance, point $D$ locates at the left arch foot, point E locates at the right arch foot, and point $F$ locates at the center of the bottom, as shown in Figure 6 . The pore pressure variations of these points with time in the working conditions 1 to 3 compared with those of the working condition without a karst cave are shown in Figure 7. The solid lines in Figure 7 represent the result of the working condition without a karst cave, while the dotted lines represent the results of the working conditions 1,2 , and 3 .

It can be seen from Figure 7 that, compared with the working condition with no karst cave, the pore water pressure at points $\mathrm{B}$ and $\mathrm{D}$ changes considerably in working conditions with a karst cave. When the pore water pressures are stable, the pore pressures at points A, C, E, and F under working conditions 1 to 3 are close to those without a karst

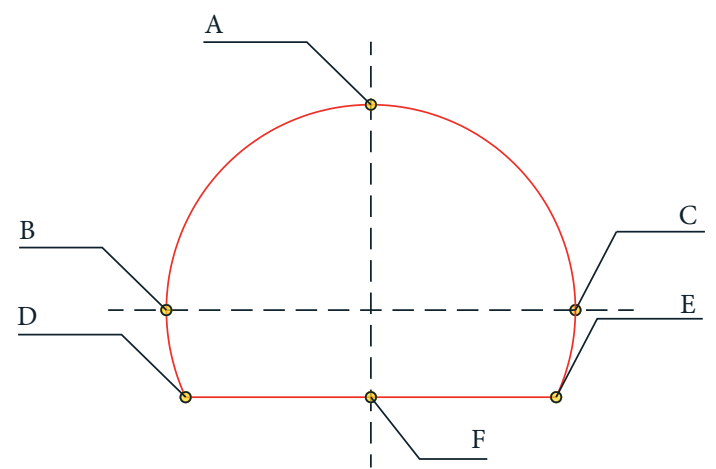

Figure 6: Layout of the monitoring points.

cave, while the pore pressures at points $\mathrm{B}$ and $\mathrm{D}$ decrease significantly. During the early stage of excavation, compared with the working condition without a karst cave, the pore pressures at points $\mathrm{B}$ and $\mathrm{D}$ drop significantly. The pore pressure at points $\mathrm{C}$ and $\mathrm{E}$ increases slightly in working condition 1 but basically does change in working condition 2 and working condition 3 .

Figure 8 shows the flow vector distribution. When there is a karst cave, the seepage paths of surrounding rock near the cave are greatly affected, accompanied by the increase in flow vector at the arch foot of the opposite side of the cave. 


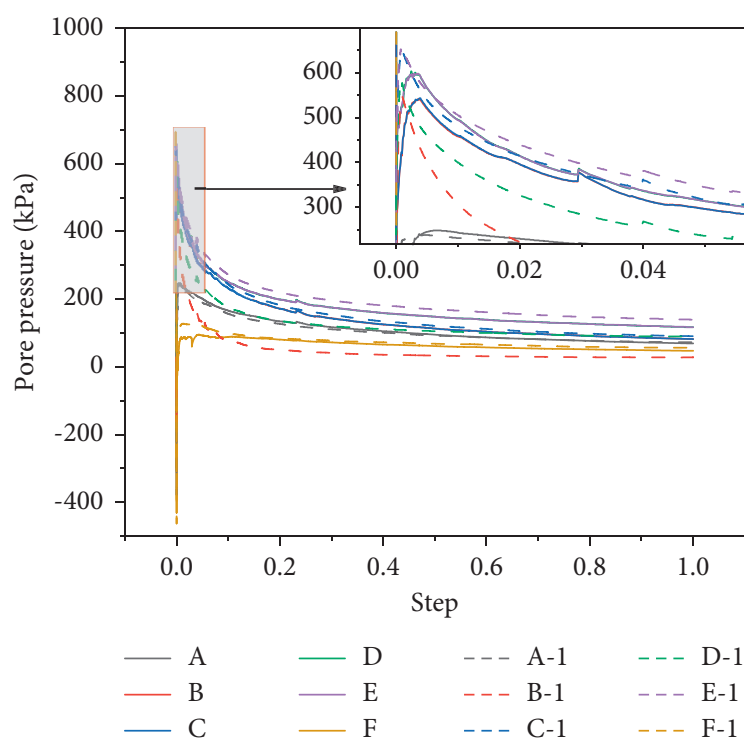

(a)

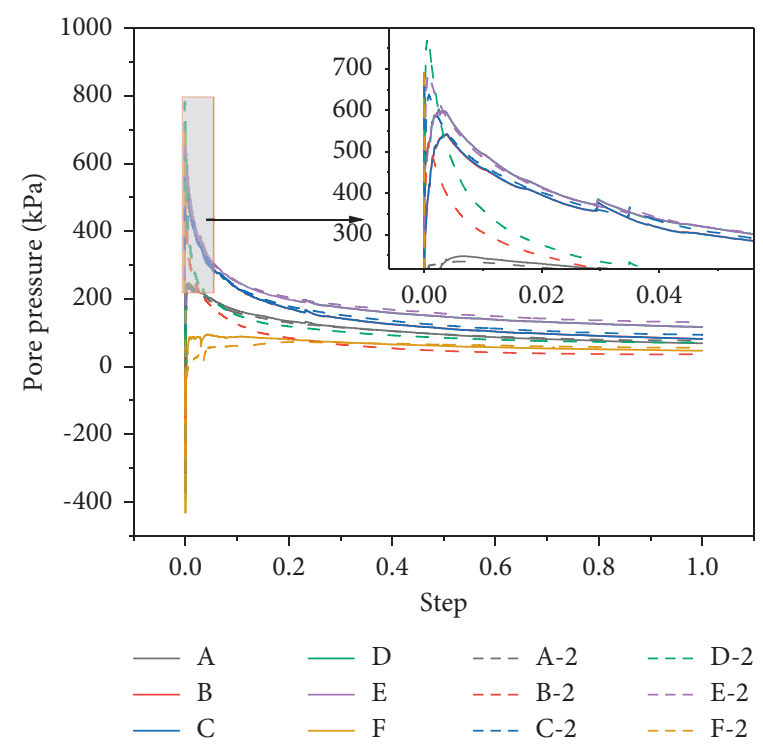

(b)

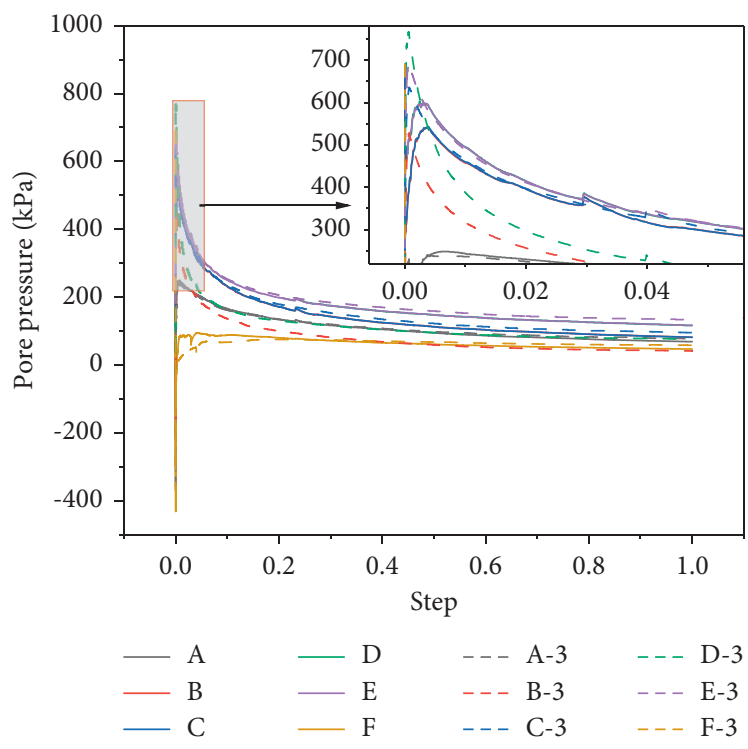

(c)

FIgURE 7: Pore water pressure variation with time of key points. (a) Working condition 1. (b) Working condition 2. (c) Working condition 3.

3.1.3. Deformation of the Surrounding Rock. To observe the deformation of the surrounding rock around the tunnel, the vertical displacement of points $\mathrm{A}$ and $\mathrm{F}$ and the horizontal displacement of points B, C, D, and E are recorded.

Figure 9 shows the development of the vertical displacement of points $\mathrm{A}$ and $\mathrm{F}$ without karst caves (the solid line) and under working conditions 1 to 3 (the dotted lines). The settlement of point A (vault) increases by $26 \%$ in working conditions 1 to 3 compared with that without a karst cave. The uplift at the bottom increases slightly, but the effect is not significant.

Figure 10 shows the development of the horizontal displacement of points B to E without karst caves (the solid line) and under working conditions 1 to 3 . When there is a karst cave on the left side of the tunnel, the horizontal displacements at point B exhibit the difference, which is the point nearest to the cave. For working condition 1, at the initial stage of excavation, the displacement of point B increases significantly. Finally, the displacement of point B increases by $45 \%$ compared with condition without cave. For working condition 2, the displacement of point B increases by $20 \%$. For working condition 3 , the increase is not obvious. It can be seen that the point $\mathrm{B}$ closest to the cave has an increase in horizontal displacement when the distance of cave to the tunnel is no more than $4 \mathrm{~m}$.

On the one hand, the existence of the cavern itself weakens the stiffness of the surrounding rock of the tunnel, and the stability is significantly reduced. On the other hand, due to the existence of karst caves, the seepage path on the 


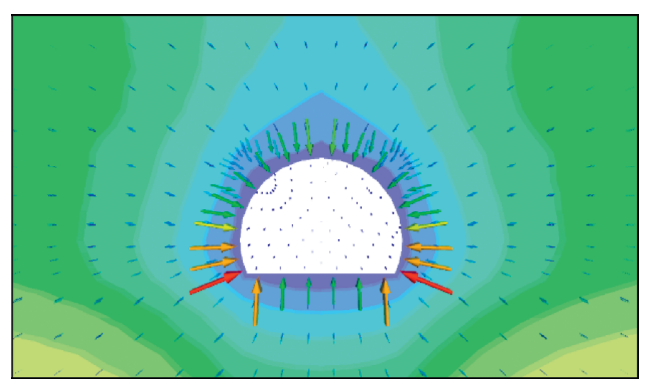

(a)

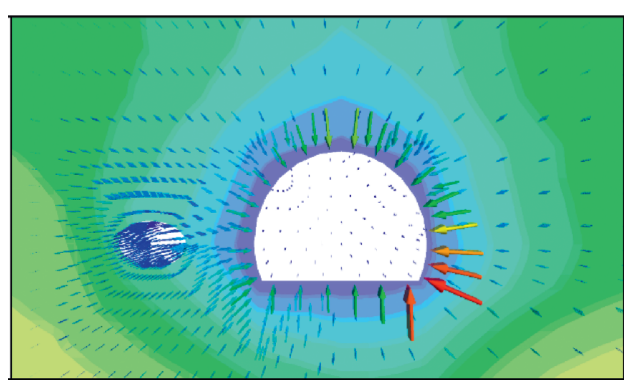

(b)

FIgURE 8: Flow vector diagram. (a) Without a karst cave. (b) With a karst cave.

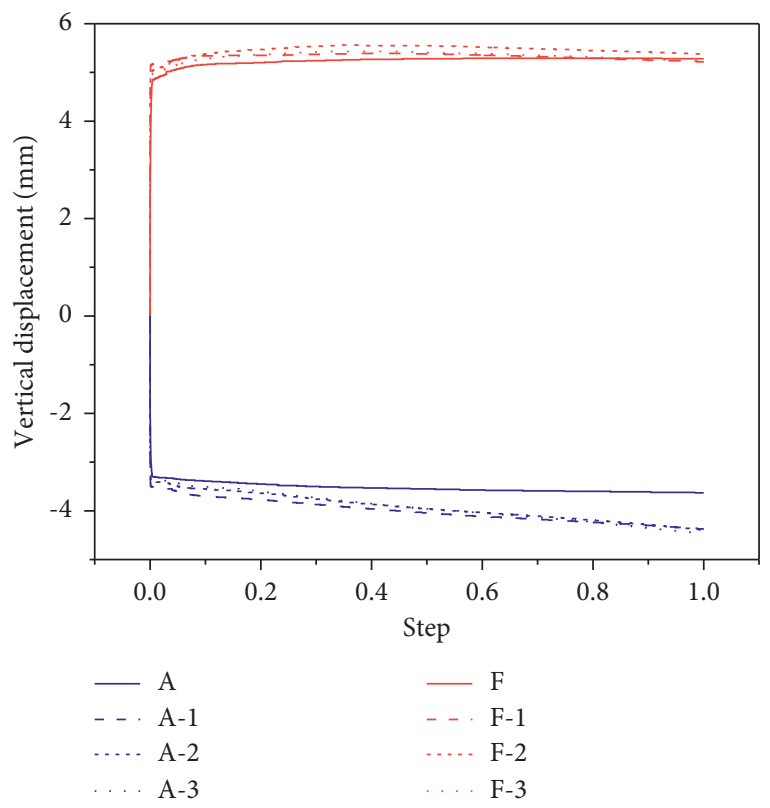

Figure 9: Vertical displacement at points A and F under working conditions 1 to 3 .

side close to the karst cave is blocked after the tunnel is excavated, and the karst cave acts as a shield. Therefore, the pore pressure at the corresponding position is significantly smaller than the pore pressure on the symmetry side. The overlying load remains unchanged, and the reduction of pore pressure causes the skeleton stress of the surrounding rock to increase correspondingly, which reduces the volumetric strain of the surrounding rock. Therefore, the displacement of the surrounding rock near the tunnel on the side of the karst cave increases.

3.1.4. Stress of the Tunnel Lining. Figure 11 shows the 1 st and 3rd principal stresses of the tunnel lining under working conditions 1 to 3 , respectively, compared with the results from the working condition without a karst cave. It can be seen that the compressive stress at the vault increases while the tensile stress at the arch bottom decreases for 3 conditions due to the cave. The compressive stress at spandrel, hance, and arch foot also increases at different degree for 3 conditions due to the cave. However, there are no definite rules for the variation in stress with the increase in the distance of cave to the tunnel. Compared with the stress distribution for the working condition without a karst cave, the principal stress distribution of the tunnel lining under working conditions 1 to 3 exhibits a nonuniform distribution.

\subsection{Influence of Karst Cave Location}

3.2.1. Stress Field of the Surrounding Rock. In working conditions 4, 5, and 6, the karst caves are located at different locations of the tunnel. Horizontal and vertical stress contour plots for working conditions 4 to 6 are shown in Figures 12 and 13.

It can be seen that when the relative position of the karst cave to the tunnel changed, the stress field of the surrounding rock has changed. The compressive stress near the cave decreased when the cave is directly above or directly below the tunnel in working conditions 4 and 5 . The stress distribution at the upper left side of the tunnel is greatly influenced in working condition 6 . For working condition 6 , the horizontal stress between the cave and the tunnel increases by about $25 \%$ due to the existence of the cave. Also, a nonuniform stress distribution is found around the tunnel when the cave is not located on the axis of symmetry of the tunnel in working condition 6 .

3.2.2. Seepage Field. The pore pressure variations of these points with time in the working conditions 4 to 6 compared with those of the working condition without a karst cave are shown in Figure 14. The solid lines in Figure 14 represent the result of the working condition without a karst cave, while the dotted lines represent the results of the working conditions 4, 5, and 6 .

Figure 14(a) shows that when the karst cave is directly above the tunnel, the pore pressure at point A decreases significantly compared with that without a karst cave; the pore pressure at points $\mathrm{B}$ and $\mathrm{C}$ decreases slightly, while the pore pressures at points $\mathrm{D}, \mathrm{E}$, and $\mathrm{F}$ basically remain unchanged. Figure 14(b) shows that when the karst cave is located directly under the tunnel, the pore pressure at point F decreases significantly compared with that without a karst cave; the pore pressures at points $\mathrm{B}, \mathrm{C}, \mathrm{D}$, and $\mathrm{E}$ decreases slightly, while the pore pressure at point A increases slightly. 


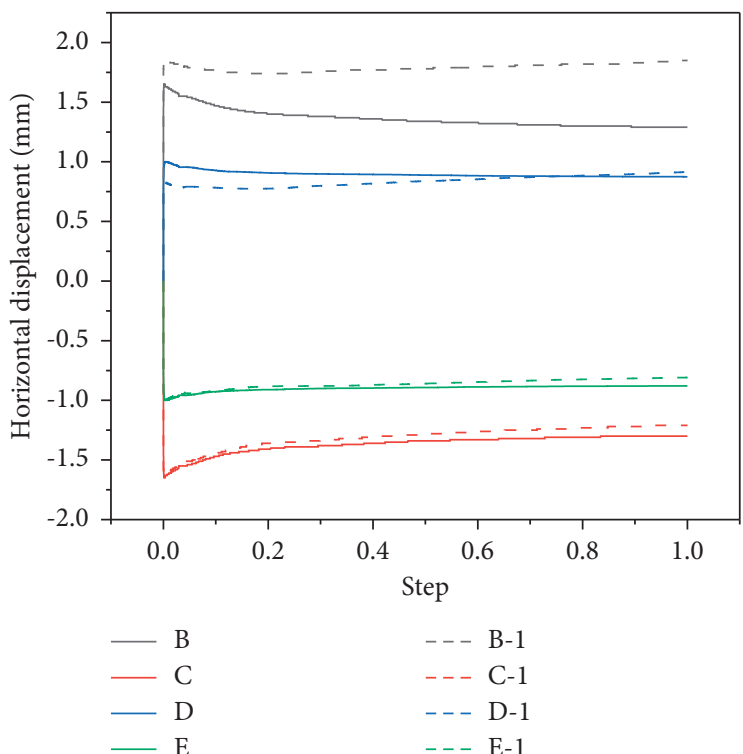

(a)
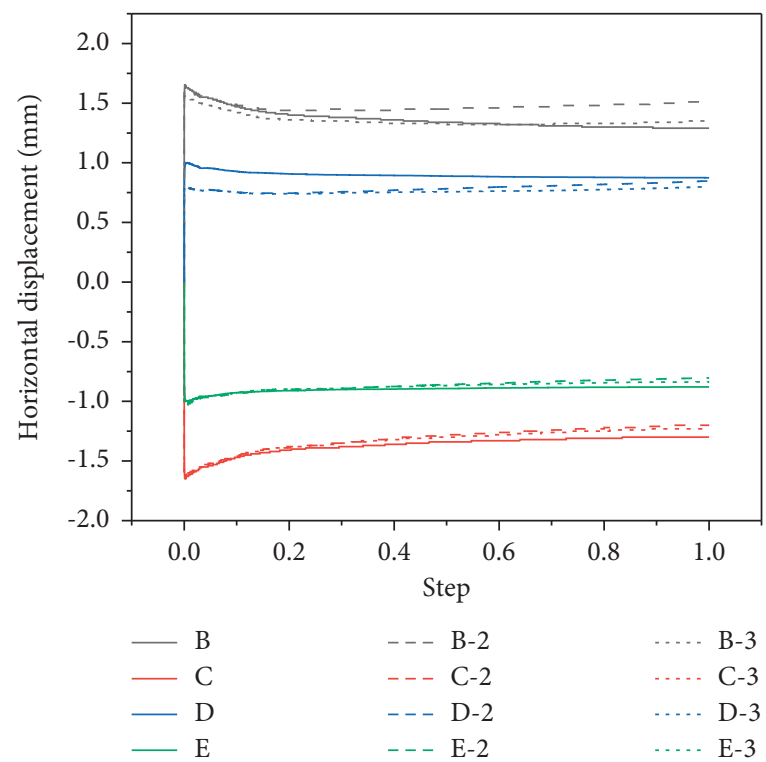

(b)

Figure 10: Horizontal displacement at the monitoring points B to E. (a) Working condition 1. (b) Working conditions 2 and 3.

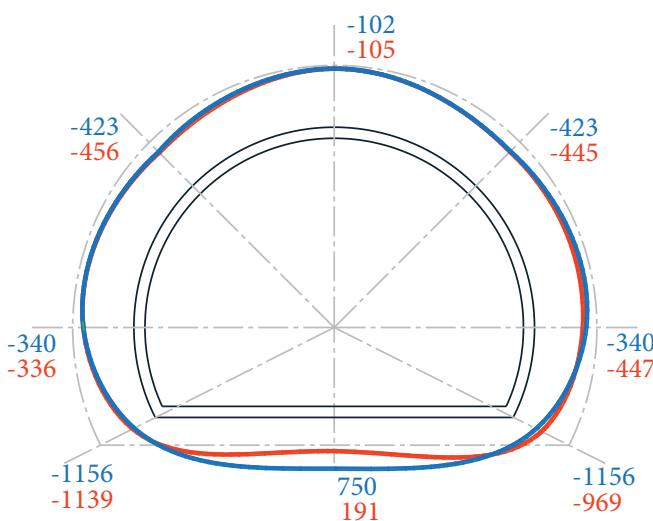

- without cave

- with cave

(A) $1^{\text {st }}$ principal stress $(\mathrm{kPa})$

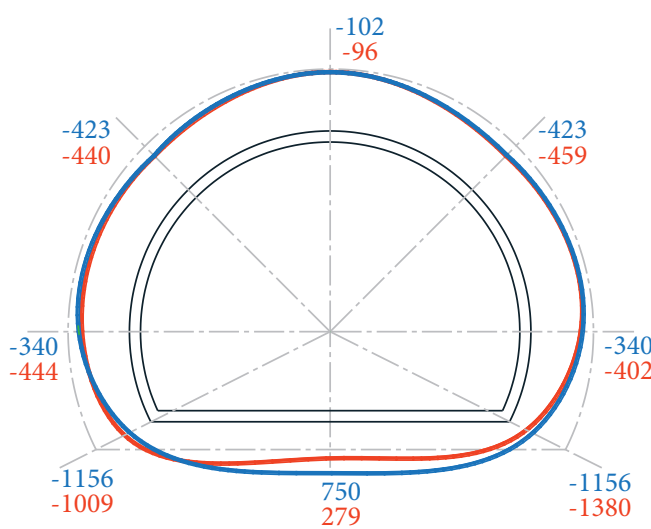

- without cave

— with cave

(A) $1^{\text {st }}$ principal stress $(\mathrm{kPa})$

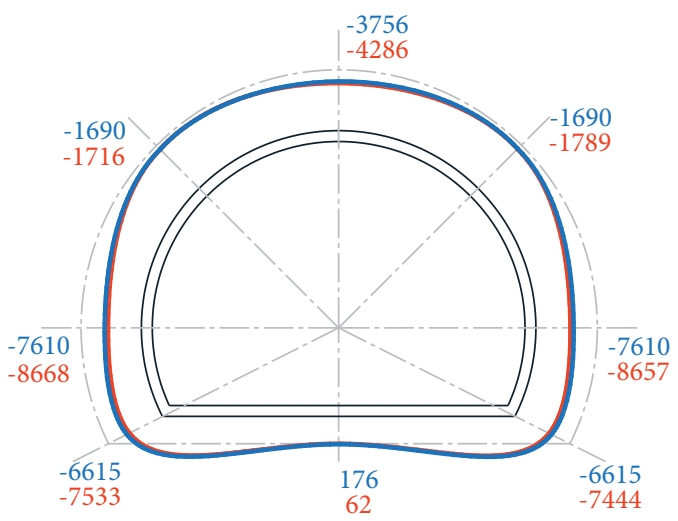

— without cave

_ with cave

(B) $3^{\text {st }}$ principal stress $(\mathrm{kPa})$

(a)

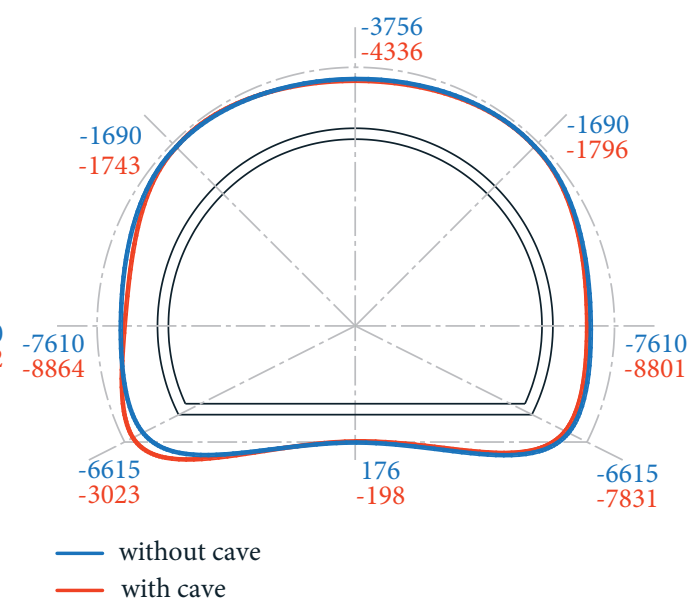

(B) $3^{\text {st }}$ principal stress $(\mathrm{kPa})$

(b)

Figure 11: Continued. 


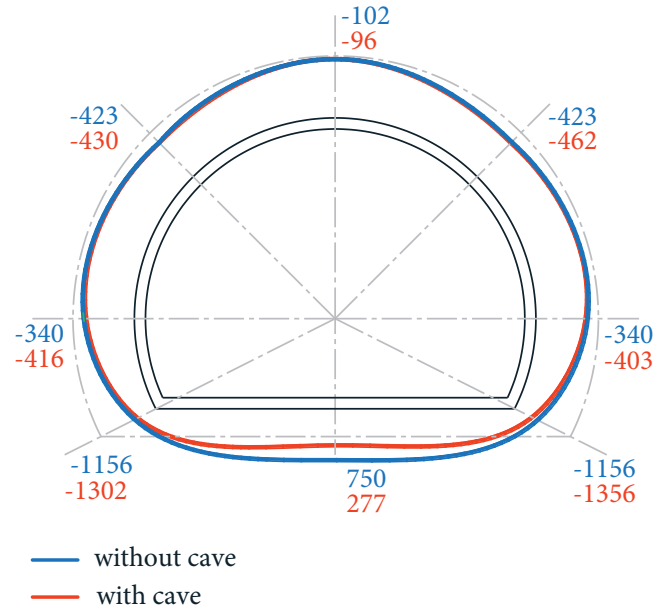

(A) $1^{\text {st }}$ principal stress $(\mathrm{kPa})$

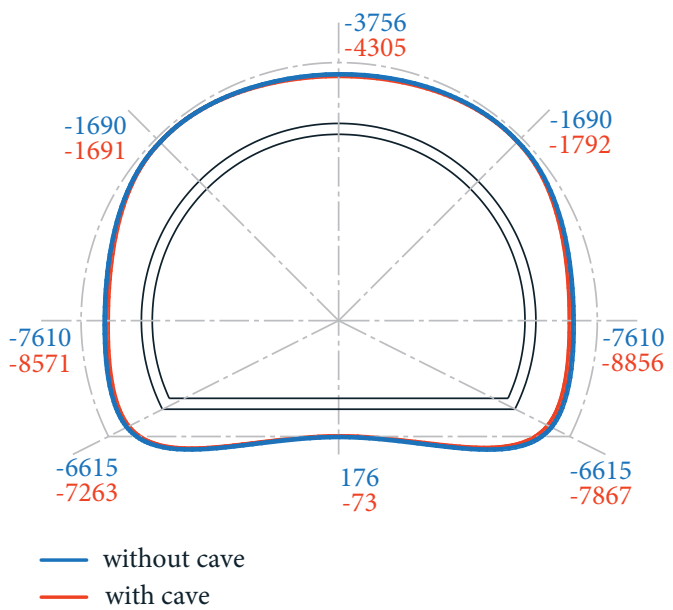

(B) $3^{\text {st }}$ principal stress $(\mathrm{kPa})$

(c)

FIgURE 11: Stress distribution of the tunnel lining under working conditions 1 to 3. (a) Working condition 1. (b) Working condition 2. (c) Working condition 3 .

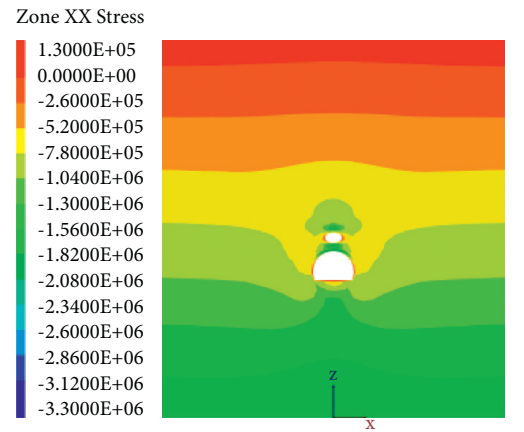

(a)

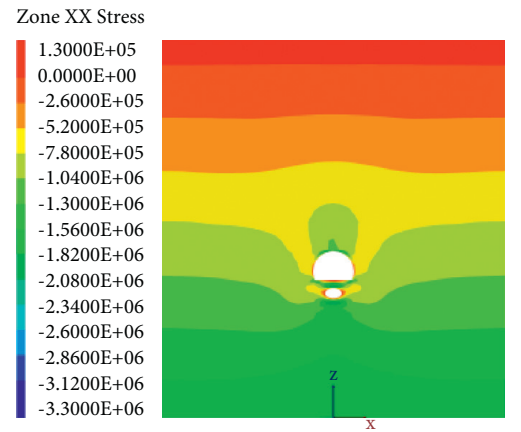

(b)

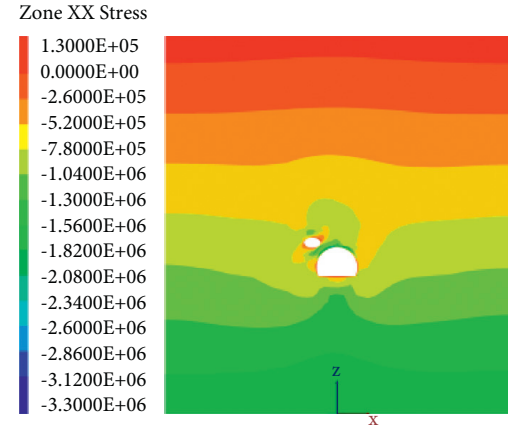

(c)

FIGURE 12: Horizontal stress contour plots. (a) Working condition 4. (b) Working condition 5. (c) Working condition 6.

Zone ZZ Stress $5.6000 \mathrm{E}+04$
$-2.1000 \mathrm{E}+05$
$-6.3000 \mathrm{E}+05$
$-1.0500 \mathrm{E}+06$
$-1.4700 \mathrm{E}+06$
$-1.8900 \mathrm{E}+06$
$-2.3100 \mathrm{E}+06$
$-2.7300 \mathrm{E}+06$
$-3.1500 \mathrm{E}+06$
$-3.5700 \mathrm{E}+06$
$-3.9900 \mathrm{E}+06$
$-4.4100 \mathrm{E}+06$
$-4.8300 \mathrm{E}+06$
$-5.2500 \mathrm{E}+06$
$-5.5000 \mathrm{E}+06$

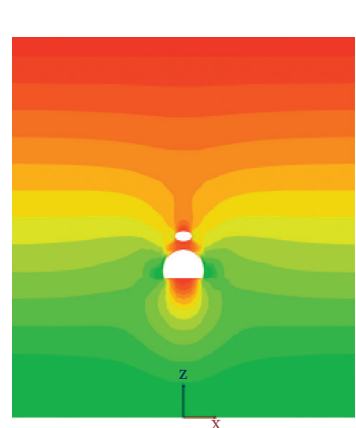

(a)
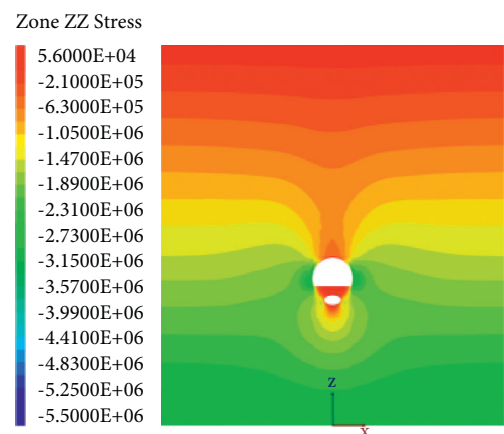

(b)

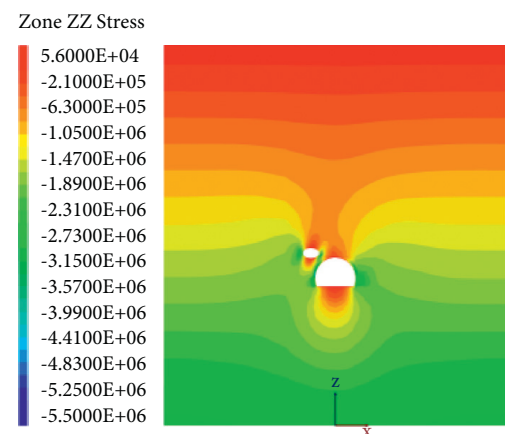

(c)

FIGURE 13: Vertical stress contour plots. (a) Working condition 4. (b) Working condition 5. (c) Working condition 6.

Figure 14(c) shows that when the karst cave is $45^{\circ}$ to the left above the oblique tunnel, the pore pressure at points $\mathrm{A}$ and $\mathrm{B}$ decreases significantly compared with those without a karst cave, while the pore pressure at point $\mathrm{D}$ decreases slightly, and the pore pressure at points $\mathrm{C}, \mathrm{E}$, and $\mathrm{F}$ basically remains unchanged. When there is a cave, the seepage flow of the surrounding rock near the cave causes the pore pressure at this location to be relatively reduced. 


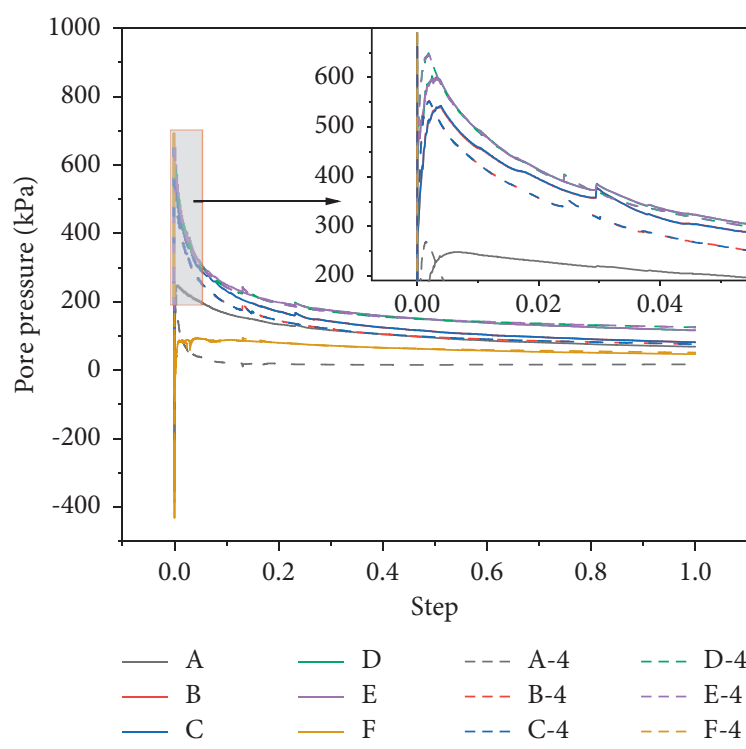

(a)

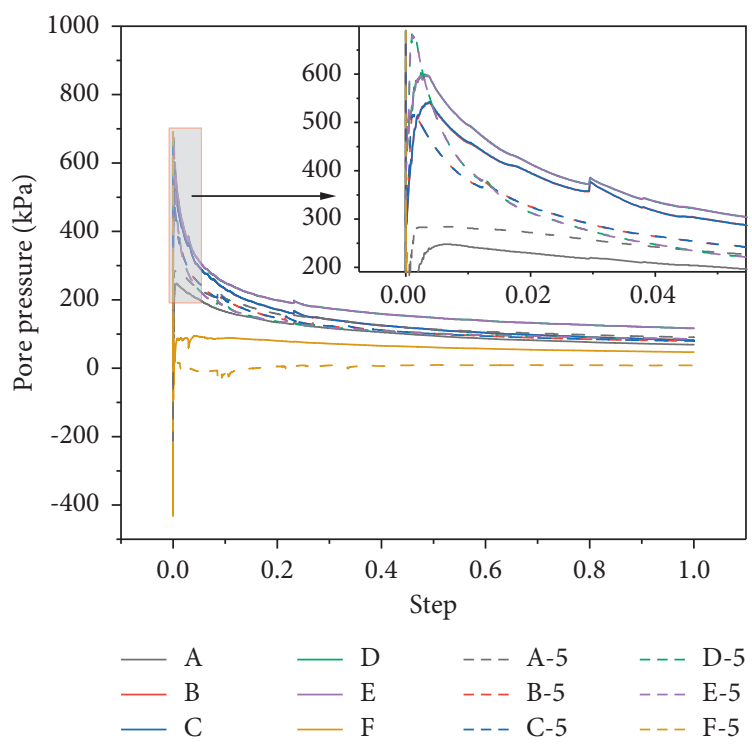

(b)

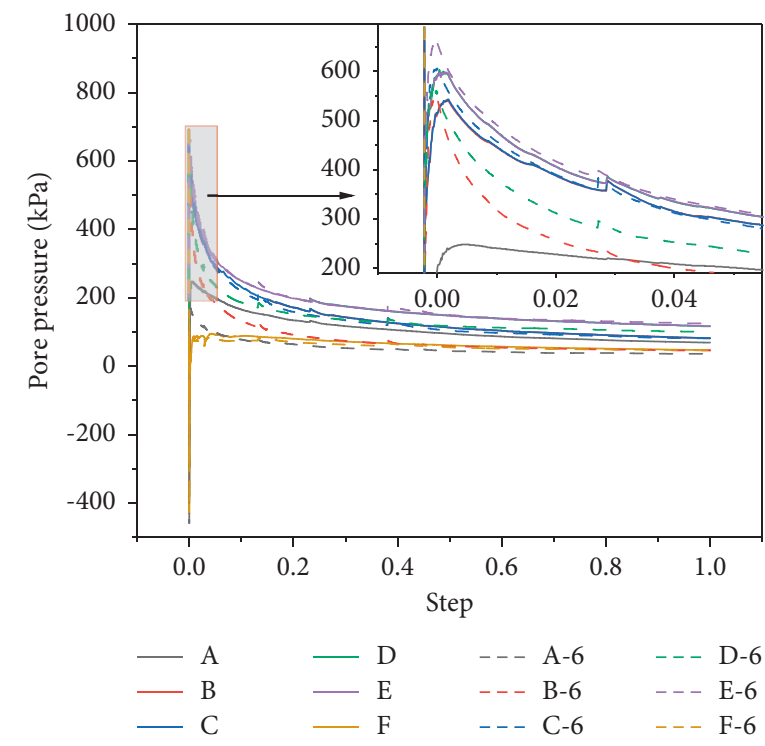

(c)

Figure 14: Comparison charts of the pore water pressure changes. (a) Working condition 4. (b) Working condition 5. (c) Working condition 6 .

3.2.3. Deformation of the Surrounding Rock. Figure 15 shows the development of the vertical displacement of points A and F without karst caves (the solid line) and under working conditions 4 to 6 (the dotted lines). Compared with the curve without a karst cave, when the karst cave locates above the tunnel, the settlement at point $\mathrm{A}$ increases and the uplift at point $\mathrm{F}$ decreases. When the karst cave locates below the tunnel, the settlement at point A decreases and the uplift at point $\mathrm{F}$ increases. When the karst cave locates in the upper left of the tunnel in condition 6, the uplift at point $F$ increases more than that in condition 4 .

Figure 16 shows the development of the horizontal displacement of points B to E without karst caves (the solid line) and under working conditions 4 to 6 . When the karst cave is located above or below the tunnel, it has little effect on the horizontal displacement at the monitoring points. Compared to the condition without a karst cave, under working condition 6 , the horizontal displacement of points $\mathrm{B}, \mathrm{C}$, and $\mathrm{E}$ decreases, while the horizontal displacement of point $\mathrm{D}$ increases.

3.2.4. Stress of the Tunnel Lining. Figure 17 shows the 1st and 3rd principal stresses of the tunnel lining under working conditions 4 to 6 , respectively, compared with the results from the working condition without a karst cave. 


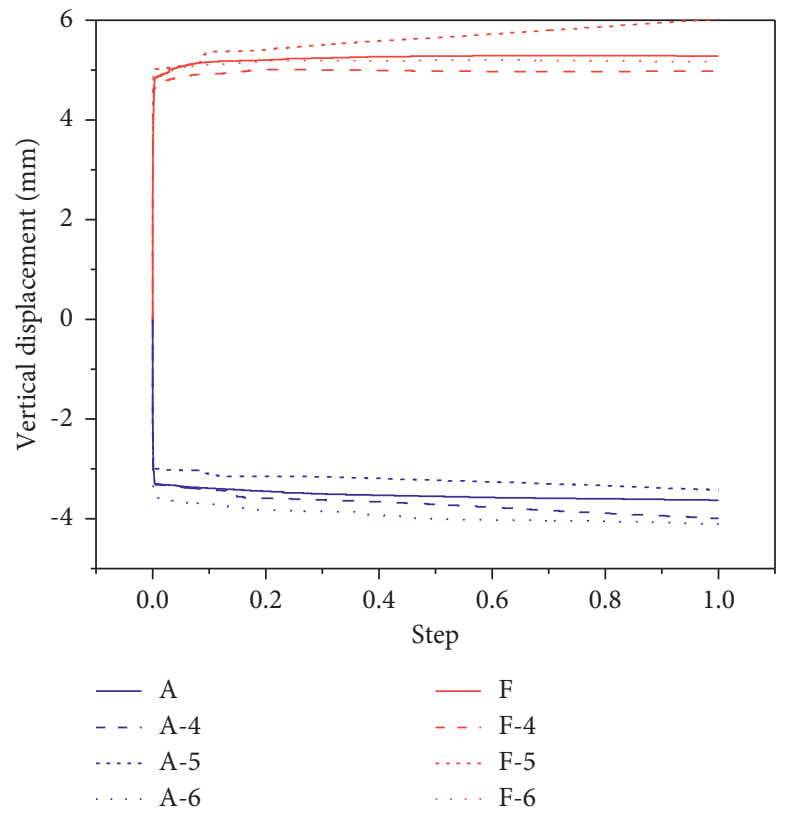

Figure 15: Vertical displacement at points A and F.

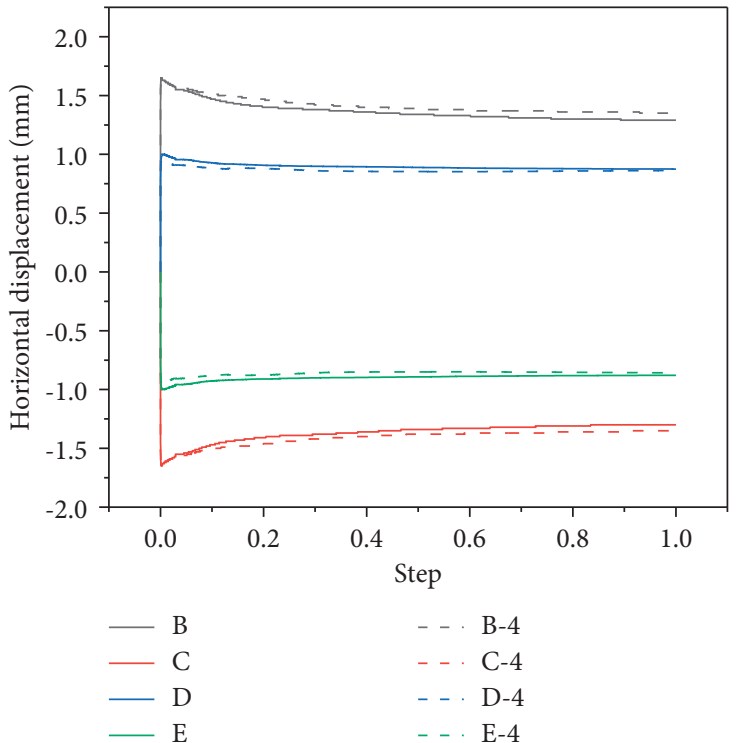

(a)

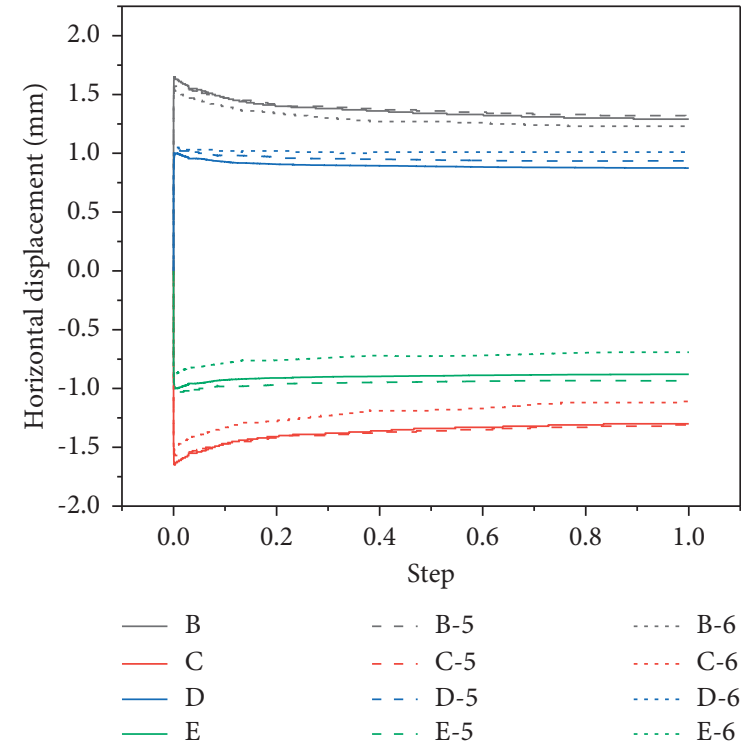

(b)

Figure 16: Horizontal displacement at the monitoring points B to E. (a) Condition 4. (b) Condition 5 and condition 6.

It can be seen from Figure 17 that when the cave locates above the tunnel, the compressive stress at the vault increases by $23 \%$. When the cave was located below the tunnel, the compressive stress at the arch foot decreases significantly by $57 \%$. When the cave locates upper left of the tunnel, the compressive stress at the vault and the left hance increases significantly by $19 \%$ and $43 \%$, respectively. 

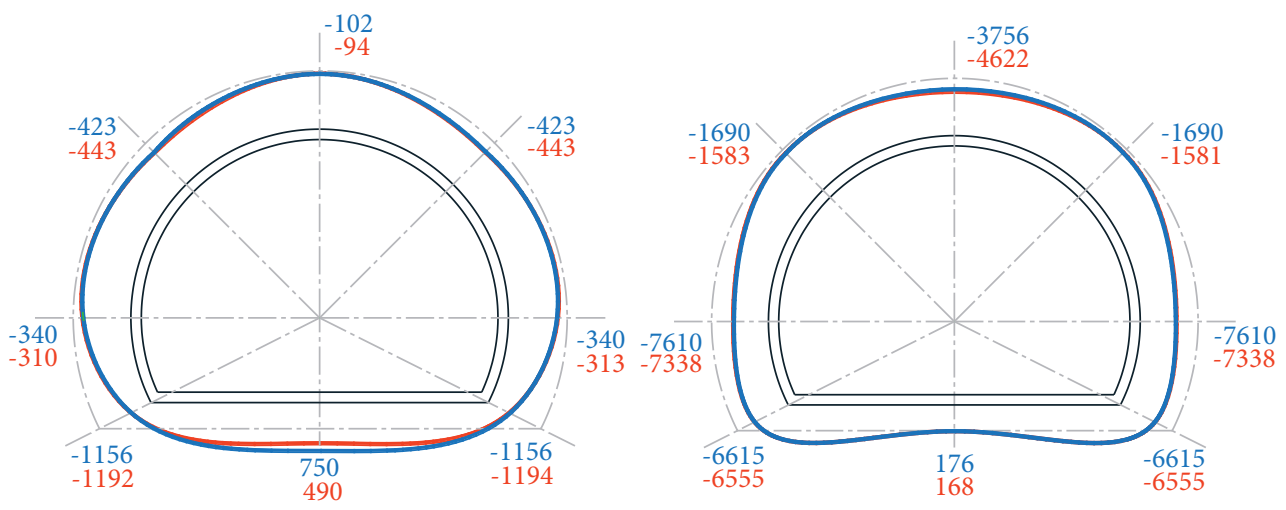

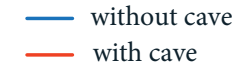

(A) $1^{\text {st }}$ principal stress $(\mathrm{kPa})$

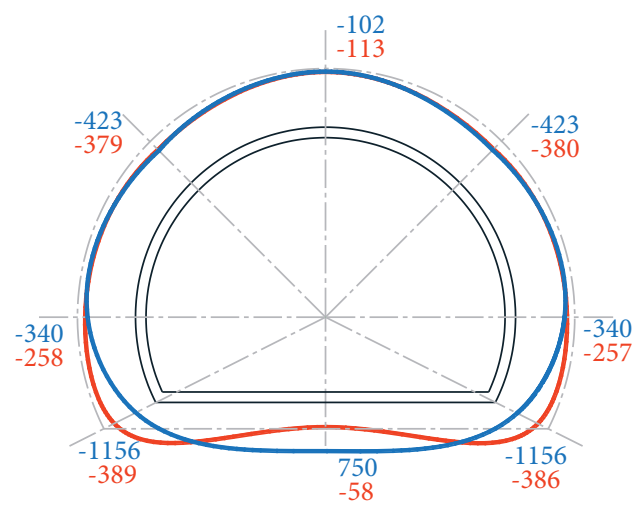

- without cave

- with cave

(A) $1^{\text {st }}$ principal stress $(\mathrm{kPa})$

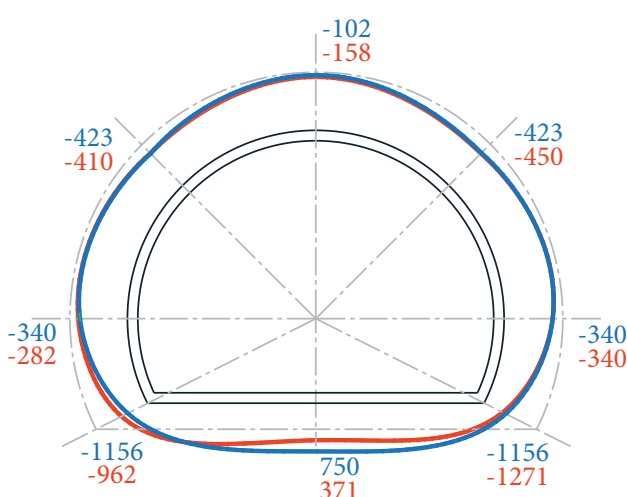

— without cave
with cave

(A) $1^{\text {st }}$ principal stress $(\mathrm{kPa})$
— without cave

_ with cave

(a)

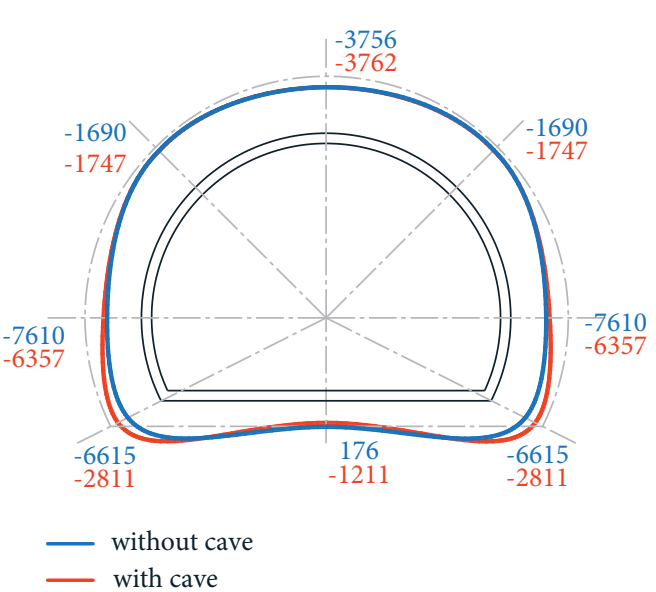

(B) $3^{\text {st }}$ principal stress $(\mathrm{kPa})$

(b)

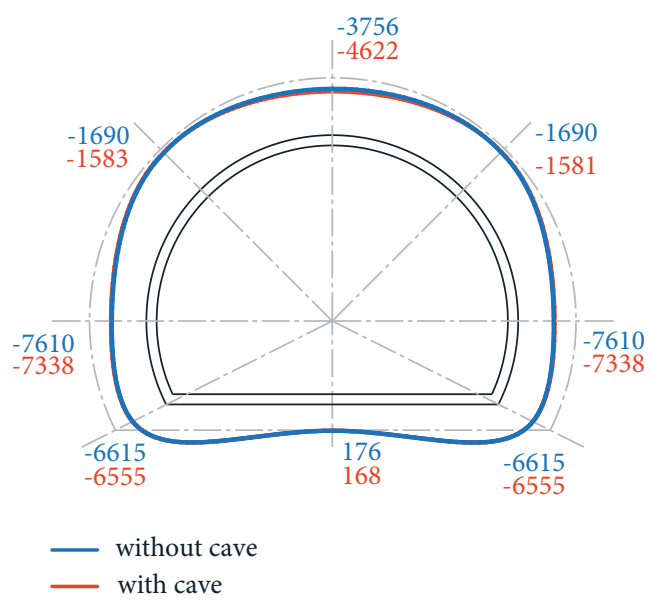

(B) $3^{\text {st }}$ principal stress $(\mathrm{kPa})$

(c)

FIgURe 17: Tunnel lining stresses under working conditions 4 to 6. (a) Working condition 4. (b) Working condition 5 . (c) Working condition 6 . 


\section{Conclusion}

A two-dimensional rock-tunnel hydromechanical model with a karst cave was established with FLAC3D finite difference software to simulate the tunnel excavation with the consideration of seepage. Numerical simulations were performed to analyze the deformation of the surrounding rock, the seepage field of the surrounding rock, and the stress of the tunnel lining, and the results were compared for scenarios when the karst cave is at different locations relative to the tunnel. The following conclusions can be obtained:

(1) Due to the existence of karst caves, the seepage path on the side close to the karst cave is blocked after the tunnel is excavated, and the karst cave acts as a shield. A cave located at the side of the tunnel results in the significant decrease of the pore pressures near the cave when the distance of the cave to tunnel is less than $2 \mathrm{~m}$. When there is a karst cave, the seepage paths of surrounding rock near the cave were greatly affected, accompanied by the increase in flow vector at the arch foot of the opposite side of the cave. When a cave is at different locations of the tunnel, the seepage flow causes the pore pressure near the cave to be reduced.

(2) A cave located at the side of the tunnel also causes the increase in settlement at the vault and outward expansion at the hance near the cave. When the karst cave was located above the tunnel the settlement at the vault increased and the uplift at the bottom decreased, otherwise the opposite. When the karst cave is located in the upper left of the tunnel, the uplift at the bottom of the tunnel increased considerably.

(3) A cave located at the upper area of tunnel results in the increase of the tunnel compressive stress near the cave, while a cave located at the lower area of tunnel results in the decrease of the tunnel compressive stress near the cave.

(4) When constructing tunnels in karst areas, the relative position and distance between the karst cave and the tunnel to be built should be ascertained in advance. For the case where the distance between the karst cave and the tunnel is very close, the reinforcement measures on the karst side of the tunnel must be strengthened to prevent large uneven deformation of the tunnel. At the same time, except for the case where the karst cave is located at the bottom of the tunnel, the vault in other working conditions is a weak point, and reinforcement measures for the vault should be strengthened.

\section{Data Availability}

Some or all data, models, or codes that support the findings of this study are available from the corresponding author upon reasonable request.

\section{Conflicts of Interest}

The authors declare that they have no conflicts of interest or personal relationships that could have appeared to influence the work reported in this study.

\section{Acknowledgments}

The authors would like to acknowledge financial support from the Natural Science Foundation of Shanghai (19ZR1418700).

\section{References}

[1] Y. Lu, Q. Liu, and F. E. Zhang, "Environmental characteristics of karst in China and their effect on engineering," Carbonates and Evaporites, vol. 28, no. 1-2, pp. 251-258, 2013.

[2] F. Gutiérrez, M. Parise, J. de Waele, and H. Jourde, "A review on natural and human-induced geohazards and impacts in karst," Earth-Science Reviews, vol. 138, pp. 61-88, 2014.

[3] S. Alija, F. J. Torrijo, and M. Quinta-Ferreira, "Geological engineering problems associated with tunnel construction in karst rock masses: the case of gavarres tunnel (Spain)," Engineering Geology, vol. 157, pp. 103-111, 2013.

[4] K. I. Song, G. C. Cho, and S. B. Chang, "Identification, remediation, and analysis of karst sinkholes in the longest railroad tunnel in South Korea," Engineering Geology, vol. 135-136, pp. 92-105, 2012.

[5] H. Wang, E. Binder, H. Mang, Y. Yuan, and B. Pichler, "Multiscale structural analysis inspired by exceptional load cases concerning the immersed tunnel of the Hong KongZhuhai-Macao bridge," Underground Space, vol. 3, no. 4, pp. 252-267, 2018.

[6] H. Wang, H. Mang, Y. Yuan, and B. L. A. Pichler, "Multiscale thermoelastic analysis of the thermal expansion coefficient and of microscopic thermal stresses of mature concrete," Materials, vol. 12, no. 17, p. 2689, 2019.

[7] H. W. Chen and C. Sha, "Stability analysis of surrounding rock and treatment structures in superlarge karst cave of naqiu tunnel," Advances in Civil Engineering, vol. 2018, Article ID 4842308, 14 pages, 2018.

[8] Y. X. Lv, Y. J. Jiang, W. Hu, M. Cao, and Y. Mao, “A review of the effects of tunnel excavation on the hydrology, ecology, and environment in karst areas: current status, challenges, and perspectives," Journal of Hydrology, vol. 586, no. 1-15, 2020.

[9] X. Huang, S. Li, Z. Xu, M. Guo, and Y. Chen, "Assessment of a concealed karst cave's influence on karst tunnel stability: a case study of the huaguoshan tunnel, China," Sustainability, vol. 10, no. 7, pp. 1-26, 2018.

[10] W. Wang, S. Gao, L. Liu, W. Wen, P. Li, and J. Chen, “Analysis on the safe distance between shield tunnel through sand stratum and underlying karst cave," Geosystem Engineering, vol. 22, no. 2, pp. 81-90, 2019.

[11] F. Huang, L. Zhao, T. Ling, and X. Yang, "Rock mass collapse mechanism of concealed karst cave beneath deep tunnel," International Journal of Rock Mechanics and Mining Sciences, vol. 91, pp. 133-138, 2017.

[12] H. Chen and C. Sha, "Stability analysis of surrounding rock and treatment structures in superlarge karst cave of naqiu tunnel," Advances in Civil Engineering, vol. 2018, Article ID 4842308, 14 pages, 2018.

[13] Y. Zhao, Q. Peng, W. Wan, W. Wang, B. Chen, and B. Chen, "Fluid-solid coupling analysis of rock pillar stability for concealed karst cave ahead of a roadway based on catastrophic 
theory," International Journal of Mining Science and Technology, vol. 24, no. 6, pp. 737-745, 2014.

[14] R. L. Shan, X. N. Zhang, and M. Lu, "Numerical application of safe thickness between a tunnel and surrounding concealed caves," Geotechnical and Geological Engineering, vol. 36, no. 1, pp. 95-104, 2018.

[15] W. Wang, S. Gao, Y. Min, L. Liu, and J. Chen, "Three-dimensional fluid-solid coupling numerical simulation of effects of underlying karst cave on shield tunnel through sand stratum," Geotechnical and Geological Engineering, vol. 37, no. 6, pp. 4825-4836, 2019.

[16] M. J. Day, "Karstic problems in the construction of milwaukee's deep tunnels," Environmental Geology, vol. 45, no. 6, pp. 859-863, 2004.

[17] V. M. Koutepov, O. K. Mironov, and V. V. Tolmachev, "Assessment of suffosion-related hazards in karst areas using GIS technology," Environmental Geology, vol. 54, no. 5, pp. 957-962, 2008.

[18] Q. L. Cui, H. N. Wu, S. L. Shen, Y. S. Xu, and G. L. Ye, "Chinese karst geology and measures to prevent geohazards during shield tunnelling in karst region with caves," Natural Hazards, vol. 77, no. 1, pp. 129-152, 2015.

[19] Q. Ai, Y. Yuan, S. Mahadevan, and X. Jiang, "Maintenance strategies optimisation of metro tunnels in soft soil," Structure and Infrastructure Engineering, vol. 13, no. 8, pp. 1093-1103, 2017.

[20] Q. Ai, Y. Yuan, S. L. Shen, H. Wang, and X. Huang, "Investigation on inspection scheduling for the maintenance of tunnel with different degradation modes," Tunnelling and Underground Space Technology, vol. 106, Article ID 103589, 2020.

[21] Z. H. Xu, J. Wu, S. C. Li, B. Zhang, and X. Huang, "Semianalytical solution to determine minimum safety thickness of rock resisting water inrush from filling-type karst caves," International Journal of Geomechanics, vol. 18, no. 2, Article ID 04017152, 2018.

[22] China Merchants Chongqing Transportation Research and Design Institute Co. LTD, Specifications for Design of Highway Tunnels, Ministry of Communications of the People Republic of China, Beijing, China, 2014.

[23] Y. F. Zhou, Study on Seepage-Stress-Damage/Crack Coupling Theory and Method for Hydraulic Tunnel, Wuhan University, Wuhan, China, 2016.

[24] Z. B. Yu, Principles of Groundwater Hydrology, Science Press, Beijing, China, 2008. 